\title{
Pertussis in children in Bloemfontein, South Africa: A 7-year retrospective review
}

\author{
U M Hallbauer, ${ }^{1}$ MB BCh, MPraxMed, DCH, MMed (Ped), FCPaed (SA); G Joubert, ${ }^{2}$ BA, MSc; Y Goosen, ${ }^{3}$ BSocSc, MSocSc \\ ${ }^{1}$ Department of Paediatrics and Child Health, Faculty of Health Sciences, University of the Free State, Bloemfontein, South Africa \\ ${ }^{2}$ Department of Biostatistics, Faculty of Health Sciences, University of the Free State, Bloemfontein, South Africa \\ ${ }^{3}$ Department of Paediatrics and Child Health, Faculty of Health Sciences, University of the Free State, Bloemfontein, South Africa
}

Corresponding author: U Hallbauer (hallbute@ufs.ac.za)

Background. Pertussis vaccination in the 1950s was associated with a decrease in the incidence of pertussis. A resurgence of pertussis has been documented, mainly in well-resourced countries since the 1990s. The burden of pertussis has not been well described in South Africa (SA). Epidemiological data are important for rational implementation of vaccination strategies.

Objective. To describe the morbidity and mortality of children with pertussis admitted to public sector hospitals in Bloemfontein, SA. Methods. A retrospective descriptive hospital-based study of children diagnosed with pertussis by polymerase chain reaction testing from April 2008 to March 2015.

Results. One hundred and eighty-three laboratory results confirmed pertussis; 105/183 children (57.4\%) were $<18$ weeks old. Clinical data, available for $154 / 183$ cases $(84.2 \%)$, showed that $141 / 154$ children (91.6\%) were admitted to hospital, of whom one-third required intensive care. Hospital admission was associated with young age $(p<0.001)$. The median hospital stay was 9.0 days (interquartile range $6-14.5$ ), and hospital stay was longer for children aged $<18$ weeks than for those aged $\geq 18$ weeks ( $p=0.006 ; 95 \%$ confidence interval $1-5$ days). Of the 154 children, 139 (90.3\%) had a cough, which lasted $\leq 7$ days in $110 / 137$ cases $(80.3 \%)$. The total white cell count was $\geq 20.0 \times 10^{9} / \mathrm{L}$ in $58 / 144$ cases (40.3\%). Eight children (5.2\%) died.

Conclusions. This case series highlights the importance of pertussis as a problem in children. Most children had a history of cough lasting $\leq 7$ days. Young infants were most severely affected, requiring prolonged hospital stay, often with admission to a paediatric intensive care unit.

S Afr Med J 2016;106(10):1042-1046. DOI:10.7196/SAMJ.2016.v106i10.10401

Pertussis is a highly contagious infection caused by the Gram-negative bacteria Bordetella pertussis and B. parapertussis. It is a vaccinepreventable disease mainly affecting the respiratory tract. Wholecell pertussis vaccines were introduced in the 1950s and resulted in a marked decrease in the incidence of pertussis worldwide. The reappearance of pertussis was predicted and has been documented mainly in developed countries since the 1990s. ${ }^{[1]}$ There are several explanations for this resurgence, the most prominent being waning immunity in the older child and adult population, shorter and lower vaccine-induced immunity after changeover from the wholecell to the acellular pertussis vaccine, and pathogen adaptation of the B. pertussis populations. ${ }^{[2]}$ The Expanded Programme on Immunisation in South Africa (SA) changed from using whole-cell to acellular pertussis vaccine in 2009. Despite the fact that pertussis is a notifiable disease in this country, data on the burden of disease before and after the changeover are extremely limited. This study was designed to describe the extent of the problem of pertussis in a hospital setting over a 7-year period in children in Bloemfontein, SA.

\section{Methods \\ Study design}

This was a retrospective descriptive hospital-based study during the period April 2008 - March 2015 (84 months). Only children whose diagnosis was confirmed with a pertussis polymerase chain reaction (PCR) test were included.

\section{Study location}

National District, Pelonomi and Universitas hospitals (primary-, secondary- and tertiary-level healthcare institutions, respectively) form the cluster of public sector hospitals in Bloemfontein associated with the academic complex of the Faculty of Health Sciences of the University of the Free State.

\section{Data collection and inclusion criteria}

Doctors working in the above settings, at their discretion, took nasal or nasopharyngeal swabs from a child if the clinical picture was suggestive of pertussis, such as a cough lasting $>14$ days, post-tussive vomiting, coughing spells, apnoea episodes or if the full blood count showed a total white cell count $\geq 20.0 \times 10^{\%} / \mathrm{L}$. Standard-sized Dacron swabs were used and the specimens were sent to the National Health Laboratory Service (NHLS) laboratory in Johannesburg, SA. PCR testing specific for insertion sequences IS481 (B. pertussis) and IS1001 (B. parapertussis) was done using a commercial kit. Tests to exclude $B$. holmesii and B. bronchiseptica were not done. On receipt of a positive pertussis PCR result, 1 - 2 weeks after the swab had been taken, clinical data were collected retrospectively from the clinical records.

Children diagnosed with pertussis were grouped by age in the report. These groups were selected in relation to timing of vaccination in SA, which occurs at 6,10 and 14 weeks of age with a booster at 18 months of age, as follows: neonates (age $\leq 4$ weeks), infants ( $>4-6$ weeks) before the first vaccination, infants ( $>6-10$ weeks) before the second vaccination, infants $(>10-14$ weeks) before the third vaccination, infants (>14-18 weeks) 4 weeks after the third vaccination, infants/toddlers ( $>18$ weeks - 18 months), and children (>18 months) after the booster vaccination dose.

\section{Statistical analysis}

Data were analysed using the SAS system, version 9.3 (Statistical Analysis Software Institute, USA). Results were summarised by means, medians, standard deviations (numerical variables), frequencies 
and percentages (categorical variables). Associations between categorical variables were analysed using relative risks (RRs) with $95 \%$ confidence intervals (CIs), $\chi^{2}$ and Fisher's exact tests. Subgroup comparisons of numerical variables were done using MannWhitney tests with 95\% CIs for median differences.

\section{Ethical considerations}

Approval for the study was granted by the Ethics Committee of the Faculty of Health Sciences of the University of the Free State (ECUFS NR 143/2008). Permission to collect the data for the study was given by the clinical heads of Pelonomi, National District and Universitas hospitals. Parental consent was waived, as this was a retrospective study based on hospital records.

\section{Results}

\section{Laboratory reports}

A total of 1259 swabs from the public health sector in Bloemfontein were recorded as received at the NHLS laboratory in Johannesburg during the 7-year period from April
2008 onwards. Of these, 183 (14.5\%) confirmed pertussis. The temporal distribution of the pertussis cases is shown in Fig. 1, with an increase in cases at the beginning of 2008 and 2010 and an obvious epidemic peak during 2011 when $96 / 183$ cases (52.5\%) were diagnosed. The results are presented against a backdrop of the laboratory-confirmed pertussis cases in SA recorded by the National Institute of Communicable Diseases (NICD) in Johannesburg for this time period (Fig. 1 and Table 1).

The organism was identified as $B$. pertussis in $173 / 183$ cases $(94.5 \%)$ and B. parapertussis in 8/183 (4.4\%), and the PCR test was positive for both species in 2 cases.

The age distribution of the children is shown in Table 2. The median age was 12.9 weeks (interquartile range (IQR) 7.6 39.6). Infants $<18$ weeks of age made up $57.4 \%$ of cases. There was an overall non-significant female preponderance of cases $(53.6 \%$; $p=0.337)$. This was significant in children aged $<18$ weeks compared with those aged $\geq 18$ weeks ( $<18$ weeks $64 / 105,61.0 \%$ females; $\geq 18$ weeks $34 / 78,43.6 \%$ females; $p=0.020$ ).

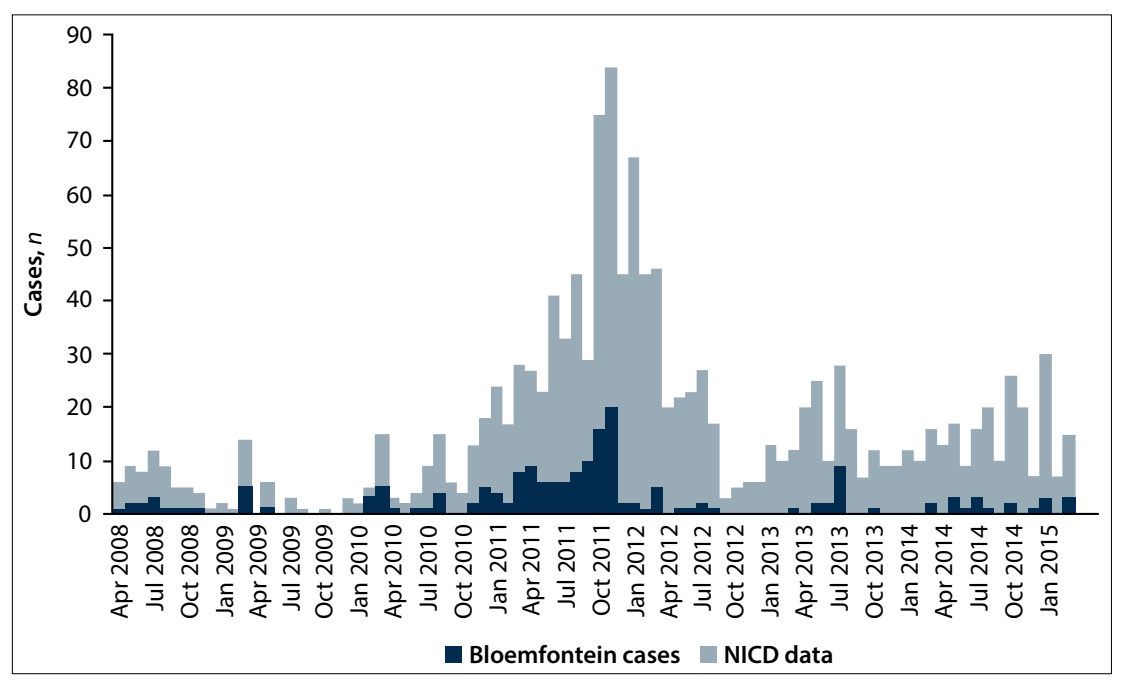

Fig. 1. Number of cases of pertussis per month recorded in Bloemfontein and number of cases recorded by the NICD for the country, April 2008 - March 2015.

\section{Clinical data}

Clinical data were available for $154 / 183$ cases (84.2\%). Of these children, 141/154 (91.6\%) were admitted and 13/154 (8.4\%) were treated as ambulatory patients. Fifty-one hospitalised children (36.2\%) required admission to a paediatric intensive care unit (PICU).

Hospital admission was associated with young age: $89 / 92$ children $<18$ weeks of age $(96.7 \%)$ required admission, whereas 52/62 children $\geq 18$ weeks of age $(83.9 \%)$ required admission ( $p=0.005$; RR 1.15; 95\% CI 1.03 - 1.29).

PICU admission was also associated with young age: $45 / 89$ children $<18$ weeks of age $(50.6 \%)$ required intensive care v. $6 / 52$ $\geq 18$ weeks of age (11.5\%) (RR 4.38; $95 \%$ CI 2.01 - 9.56; $p<0.001$ ).

The median hospital stay was 9.0 days (IQR 6 - 16.0, range 2 - 74). The median total duration of hospitalisation for children aged $<18$ weeks and $\geq 18$ weeks was 10.0 and 8.0 days, respectively ( $95 \%$ CI $1-5$ days; $p=0.006$ ) (Table 3). Two children were excluded from this analysis as they had prolonged hospital stays (not PICU) due to other problems: one child required pneumonectomy for complications of concomitant pulmonary tuberculosis, and the other was newly diagnosed with congenital cyanotic heart disease.

It was difficult to ascertain from the clinical notes whether there were symptomatic contacts, but only $18 / 154$ children $(11.7 \%)$

Table 2. Age distribution of children diagnosed with pertussis $(N=183)$

\begin{tabular}{ll}
\hline Age group & Cases, $\boldsymbol{n}(\%)$ \\
\hline $0-28$ days & $9(4.9)$ \\
$29-42$ days & $21(11.5)$ \\
$43-70$ days & $37(20.2)$ \\
$71-98$ days & $27(14.8)$ \\
99 days $-<18$ weeks & $11(6.0)$ \\
18 weeks -18 months & $60(32.8)$ \\
$\geq 19$ months & $18(9.8)$
\end{tabular}

Table 1. Total number of pertussis cases diagnosed per year: Bloemfontein cases and specimens submitted, and available NICD data

\begin{tabular}{|c|c|c|c|c|c|c|c|c|c|}
\hline & $\begin{array}{l}2008 \\
\text { (Apr - Dec) }\end{array}$ & $\begin{array}{l}2009 \\
\text { (Jan - Dec) }\end{array}$ & $\begin{array}{l}2010 \\
\text { (Jan - Dec) }\end{array}$ & $\begin{array}{l}2011 \\
(\text { Jan - Dec) }\end{array}$ & $\begin{array}{l}2012 \\
\text { (Jan - Dec) }\end{array}$ & $\begin{array}{l}2013 \\
\text { (Jan - Dec) }\end{array}$ & $\begin{array}{l}2014 \\
(\text { Jan - Dec) }\end{array}$ & $\begin{array}{l}2015 \\
\text { (Jan - Mar) }\end{array}$ & Total \\
\hline $\begin{array}{l}\text { Specimens } \\
\text { submitted, } \\
\text { Bloemfontein, } n\end{array}$ & 77 & 120 & 136 & 326 & 206 & 141 & 241 & 12 & 1259 \\
\hline $\begin{array}{l}\text { Confirmed pertussis, } \\
\text { Bloemfontein, } n\end{array}$ & 12 & 6 & 22 & 96 & $13^{*}$ & 15 & 13 & 6 & 183 \\
\hline $\begin{array}{l}\text { Confirmed pertussis, } \\
\text { NICD data, } n\end{array}$ & 60 & 25 & 74 & 374 & 274 & 156 & 163 & 46 & 1172 \\
\hline
\end{tabular}


had a definite record of a coughing contact in the household.

Of the 139/154 children (90.3\%) who presented with a cough, $110 / 137(80.3 \%)$ had a cough lasting $\leq 7$ days, $11 / 137(8.0 \%)$ had a cough duration of 8 - 20 days and 16/137 (11.7\%) had a cough duration of $\geq 21$ days. Other recorded symptoms compatible with classic pertussis included post-tussive vomiting in $60 / 154$ cases $(39.0 \%)$, cough paroxysms in $23 / 154$ (14.9\%), convulsions in 24/154 (15.6\%), apnoea in $22 / 154(14.3 \%)$ and a whoop in 7/154 (4.5\%). Two of the 7 children with a whoop were $<14$ weeks of age, and the other 5 were aged between 7 months and 4 years. All the infants presenting with apnoea, except one 10-month-old child who had chronic lung disease, were $\leq 12$ weeks of age. Of the above symptoms, apnoea was significantly more common in children aged $<18$ weeks than in those aged $\geq 18$ weeks $(22.8 \%$ v. $1.6 \% ; p<0.001)$.

Other symptoms, not classically recorded for pertussis, were noted: fever in 41/154 (26.6\%), diarrhoea in 23/154 (14.9\%) and stridor or a croup syndrome in $6(3.9 \%)$, while $10(6.5 \%)$ presented with circulatory shock. Of these symptoms, fever was less common in children aged $<18$ weeks than in those aged $\geq 18$ weeks $(18.5 \%$ v. $38.7 \%$; $p=0.005)$. The most common comorbidities were malnutrition in $25 / 154$ cases $(16.2 \%)$, concomitant tuberculosis (microbiologically proven) in $11 / 154(7.1 \%)$ and invasive pneumococcal disease in $2 / 154$ (1.3\%). Children aged $<18$ weeks were less commonly malnourished (7.6\% v. $29.0 \% ; p<0.001)$ and less commonly had tuberculosis $(3.9 \%$ v. $12.9 \%$; $p=0.029)$ than those aged $\geq 18$ weeks.

Full blood count results were available for 144/154 children (93.5\%). Total white cell counts (WCCs) ranged from 2.18 to $85.0 \times$ $10 \%$ L and in $58 / 144$ cases (40.3\%) were $\geq 20.0 \times 10^{9} / \mathrm{L}$. A lymphocyte predominance was found in $52 / 86(60.5 \%)$ of children with a white cell count $<20.0 \times 10^{9} / \mathrm{L}$ and in $27 / 58$ (46.6\%) with a white cell count $\geq 20.0 \times 10^{9} / \mathrm{L}$ $(p=0.100)$.

Twenty-two of the 154 children (14.3\%) were HIV-infected, of whom 12 (54.5\%) were already receiving antiretroviral therapy; 91 (59.1\%) were HIV-uninfected, and the HIV status was unknown or results were not available in 41 (26.6\%). Among the children with known HIV status who were admitted

Table 3. Comparison of duration of total hospital stay and PICU stay in children aged $<18$ weeks and $\geq 18$ weeks

\begin{tabular}{lllll}
\hline & All ages & $<\mathbf{1 8}$ weeks & $\geq \mathbf{1 8}$ weeks & $p$-value \\
\hline $\begin{array}{l}\text { Total hospitalisation days (incl. PICU) } \\
\left(N=139^{*}\right)\end{array}$ & & & & 0.006 \\
$\quad$ Median & 9 & 10.0 & 8.0 & \\
$\quad$ Mean & 14.2 & 15.6 & 11.8 & \\
$\quad$ Range & $2-74$ & $2-74$ & $2-67$ & \\
Total PICU days $(N=51)$ & & & & 0.155 \\
$\quad$ Median & 10.0 & 11.0 & 7.5 & \\
$\quad$ Mean & 12.0 & 12.7 & 7.8 & \\
$\quad$ Range & $3-43$ & $3-43$ & $3-13$ & \\
*Two children were excluded from this analysis (see text). & & &
\end{tabular}

Table 4. Details of pertussis deaths (all associated with B. pertussis)*

\begin{tabular}{|c|c|c|c|c|c|c|c|}
\hline Case no. & $\begin{array}{l}\text { Date of } \\
\text { admission }\end{array}$ & $\begin{array}{l}\text { Age }(w k) \text { at } \\
\text { diagnosis and } \\
\text { gender }\end{array}$ & $\begin{array}{l}\text { Highest } \\
\text { recorded total } \\
\text { WCC }\left(\times 10^{9} / \mathrm{L}\right)\end{array}$ & $\begin{array}{l}\text { Day of death } \\
\text { after admission }\end{array}$ & HIV status & $\begin{array}{l}\text { Symptoms on } \\
\text { admission }\end{array}$ & $\begin{array}{l}\text { Morbidities associated with } \\
\text { death }\end{array}$ \\
\hline 1 & Sept 2008 & $8, \mathrm{~F}$ & 72.5 & 7 & Unknown & $\begin{array}{l}\text { Cough } 3 \text { days, } \\
\text { dyspnoea, } \\
\text { apnoea, } \\
\text { convulsions }\end{array}$ & $\begin{array}{l}\text { Hypoglycaemia, myocarditis, } \\
\text { hyperviscosity syndrome, acute } \\
\text { kidney injury, Escherichia coli } \\
\text { sepsis, hypocalcaemia, raised } \\
\text { transaminases }\end{array}$ \\
\hline 2 & Aug 2010 & $6, \mathrm{~F}$ & 85.0 & 13 & Uninfected & $\begin{array}{l}\text { Dyspnoea, } \\
\text { excessive } \\
\text { salivation }\end{array}$ & $\begin{array}{l}\text { Pneumonia, anaemia, } \\
\text { hyperviscosity, nosocomial } \\
\text { Pseudomonas infection }\end{array}$ \\
\hline 3 & April 2011 & $12, \mathrm{M}$ & 69.4 & 7 & Uninfected & $\begin{array}{l}\text { Cough } 3 \text { weeks, } \\
\text { apnoea }\end{array}$ & $\begin{array}{l}\text { Pneumonia, myocarditis, } \\
\text { hyperviscosity }\end{array}$ \\
\hline 4 & Sept 2011 & $10, \mathrm{~F}$ & $<20.0$ & 21 & $\begin{array}{l}\text { Exposed, } \\
\text { uninfected }\end{array}$ & Cough 4 days & $\begin{array}{l}\text { Circulatory shock, anaemia, } \\
\text { diarrhoea, hypoglycaemia }\end{array}$ \\
\hline 5 & Oct 2011 & $27, \mathrm{~F}$ & 37.5 & 12 & Uninfected & $\begin{array}{l}\text { Convulsions, } \\
\text { dyspnoea }\end{array}$ & $\begin{array}{l}\text { Severe malnutrition with } \\
\text { cellulitis of hand (surgical ward), } \\
\text { possible nosocomial pertussis }\end{array}$ \\
\hline 6 & Mar 2012 & $11, \mathrm{~F}$ & $<18.9$ & 3 & Uninfected & Cough 5 days & $\begin{array}{l}\text { Pneumonia, respiratory } \\
\text { failure, shock }\end{array}$ \\
\hline 7 & Dec 2012 & $6, \mathrm{~F}$ & 62.4 & 4 & $\begin{array}{l}\text { Exposed, } \\
\text { uninfected }\end{array}$ & $\begin{array}{l}\text { Cough } 2 \\
\text { days, apnoea, } \\
\text { convulsions }\end{array}$ & Pneumonia, convulsions \\
\hline 8 & Jan 2015 & $14, \mathrm{~F}$ & $<17.8$ & 10 & Infected & $\begin{array}{l}\text { Cough } 4 \text { days, } \\
\text { dyspnoea, fever }\end{array}$ & $\begin{array}{l}\text { Pneumonia, respiratory } \\
\text { failure }\end{array}$ \\
\hline
\end{tabular}


to hospital, there was no statistical difference regarding rates of admission to the PICU between HIV-infected children (9/22, 40.9\%) and those who were HIV-uninfected $(36 / 88 ; 40.9 \%)(p=1.000)$. The median length of PICU stay was 14 days and 8.5 days in HIV-infected and HIV-uninfected children, respectively $(p=0.101)$

\section{Outcomes of pertussis}

Eight children $(5.2 \%)$ died, 6 of whom had been admitted to a PICU; their ages ranged from 6 to 14 weeks, except for one who was 6 months old. Five children had very high WCCs (Table 4). Five children required readmission for ongoing illness. No data were available regarding duration of symptoms after discharge.

\section{Discussion}

This is the first reported hospital-based case series of children with pertussis in SA and highlights the significant morbidity and mortality associated with the disease. The last published report of pertussis in SA, an outbreak investigation, was from Cape Town in 1991. ${ }^{[3]}$ What was initially thought to be an outbreak in Bloemfontein, noted by doctors in both the public and the private sector, has been shown to be an ongoing epidemic with a cyclical pattern, with the highest incidence of cases documented in the last quarter of 2011, both in Bloemfontein and nationally. ${ }^{[4]}$ This peak in late 2011 and 2012 has also been documented in the UK ${ }^{[5]}$ It is not possible to comment on a seasonal trend, although the data over the 7 years show an increase of cases in autumn.

The Division of Public Health Surveillance and Response at the NICD has provided data on laboratory-confirmed pertussis cases available for the same time period for the whole country. It also includes data sent to the NICD from private sector laboratories. Of the total number of cases recorded by the NICD, 183/1 172 (15.6\%) were identified in the public healthcare sector in Bloemfontein. This is a large proportion considering that according to the 2011 census, the estimated population of the Mangaung metropolitan municipality (to which Bloemfontein belongs) made up $1.4 \%$ of the total population of SA. ${ }^{[6]}$

As expected, $B$. pertussis was the causative organism in most cases and $B$. parapertussis occurred in only a small number of cases. This has also been found in other studies. ${ }^{[7]}$

Table 2 shows that $105 / 183$ children $(57.4 \%)$ were aged $<18$ weeks. This group represents infants who have not yet received the complete primary series of pertussis vaccine. The youngest children tended to have more severe disease, with most requiring hospital admission. Half of the infants $<18$ weeks of age required admission to the PICU. We did not have access to vaccine data for the children described in this case series, but would expect that, had vaccine coverage been optimal and timeous, this group of infants would probably have contributed a smaller proportion of the cases overall. Coverage of the third vaccine (DTP3 or DTP/Hib/polio/HepB3) at 14 weeks has been recorded to be $>90 \%$ in the Free State for some of the years $(2007,2008,2011,2012)$ included in this study. ${ }^{[8]}$ A study in the Western Cape reported that $<20 \%$ of second vaccinations, third combined vaccinations and the 18 -month vaccination were given on time. ${ }^{[9]}$ About one in 10 of the children diagnosed with pertussis was aged $>18$ months. If vaccine coverage was complete in this group, this would suggest that the vaccine effectiveness was not optimal.

The duration of hospital stay (median 9 days) was longer than that reported from a similar study in Switzerland (median 6 days), and this was more marked in infants $<18$ weeks of age. Infants admitted to the PICU also had a prolonged stay. Importantly, HIV infection did not influence the morbidity or length of stay of the infants. Morbidity is high in pertussis, and the mortality rate was $5.2 \%$ in this cohort. ${ }^{[10]}$ The mortality for hospitalised children with lower respiratory tract disease at this site during the years of the study has been $4-5 \%$.

It is important to note that most children presented with a cough of $<1$ week's duration, and some did not have a cough. The World Health Organization clinical case definition of pertussis requiring a cough of $>2$ weeks' duration would underestimate the burden of pertussis in the absence of laboratory confirmation and may require revision. ${ }^{[11,12]}$ Apnoea occurred mainly in young infants, but not exclusively. Of interest is that some children presented with a croup-like syndrome, and also with fever or diarrhoea. These are not usually described with pertussis. Some children had significant comorbidities (malnutrition, tuberculosis, other bacterial infections and HIV infection), which could obscure the diagnosis of pertussis.

Another classic pointer to the diagnosis of pertussis is a high white cell count. ${ }^{[11]}$ In this group of children, $40.3 \%$ had a white cell count $\geq 20.0 \times 10^{9} / \mathrm{L}$, also found in more than half of the children who died. We did not have routine full blood count reports in many cases to enable us to comment on the presence of atypical lymphocytes.

\section{Study limitations}

This case series and the results provided by the NICD include only laboratory-confirmed pertussis cases. Bias from lack of clinical suspicion with no laboratory confirmation probably contributes to the underestimation of the burden of pertussis, both nationally and in this case series. Only patients who were ill enough to consult a medical doctor had a pertussis swab taken, and not every child with a respiratory complaint had a pertussis swab taken. There were no standard operating procedures in place regarding when pertussis swabs should be taken, and not every doctor was equally aware of the pertussis problem.

In 2012 the NHLS laboratory experienced problems with contamination and was unable to process some specimens, and several of these could not be repeated as the patients had been discharged. This may also have resulted in an under-recording of cases.

As the swabs were sent to Johannesburg for the PCR tests, we were notified of positive results 1 - 2 weeks after the swab had been taken and then retrieved the hospital records. The vaccination history of the children was not reliably recorded in the clinical notes, and some mothers did not have the child's Road To Health book with them at the time of admission. We also could not obtain reliable figures of vaccination coverage in this area for these years, although figures for the Free State have been published by the Health Systems Trust for some of the years. ${ }^{[8]}$ The pertussis problem reported in this study therefore cannot be evaluated in relation to vaccination coverage.

\section{What the study contributes}

The study shows the cycle of troughs and peaks of pertussis over a 7 -year period. This correlates with the data from the NICD and is a reasonable reflection of the pertussis problem that almost certainly has been occurring in the whole country but may have passed undiagnosed in many areas except for 'sporadic' cases which were reported in the NICD communiques. ${ }^{[13-16]}$ This study shows the 'tip of the ears of the hippopotamus', and the burden of pertussis is probably much larger than what this case series has documented. The burden of disease is carried by young infants, who have a prolonged hospital stay and a high rate of PICU admission.

\section{Recommendations}

To plan rational interventions, surveillance for pertussis needs to improve, not only among children but also among adolescents and adults. Data from other countries indicate that adolescents and adults 
do get pertussis and act as reservoirs for transmission to infants and children.

Maternal vaccination at the beginning of the third trimester of pregnancy is being implemented in many countries to reduce the burden of pertussis in early infancy. This is certainly an attractive option and has been shown to be cost-effective. Vaccination of mothers (postnatal) and other household members (cocooning) is another possible, but less effective, intervention. These immunisation measures would protect the young infant, who is most at risk of developing severe pertussis disease. ${ }^{[17,18]}$ Consideration should also be given to vaccination of healthcare workers, especially those working with infants. ${ }^{[19]}$

\section{Conclusions}

This case series of pertussis in Bloemfontein shows the cyclical pattern of the disease over 7 years with pronounced outbreak activity in 2011 through 2012, and documents a large proportion of the country's total number of diagnosed cases. Many children did not have a cough of at least 2 weeks' duration. Young infants were most severely affected, requiring prolonged hospital stay with a large percentage requiring PICU admission.

Author contributions. UMH conceived and developed the study, wrote the study protocol, collected the clinical data, participated in data analysis, interpreted the results, and wrote and checked the final manuscript. GJ contributed to the study protocol, undertook the data analysis, contributed to the interpretation of results and contributed to and checked the final manuscript. YG contributed to the study protocol, collated the data and checked the final manuscript.

Funding. No external funding was required for the study. All investigations were part of routine case management.

Acknowledgements. We acknowledge the following for their contributions to the case series of this 7-year period: (i) doctors who suspected pertussis, for taking swabs for pertussis PCR testing to confirm the diagnosis; (ii) for advice and regularly emailing results to the first author (UH) over the years: E Elliott, M Pieters (Department of Medical Microbiology, University of the Free State and NHLS, Bloemfontein), and medical scientists at NHLS, Infection Control Services, Johannesburg (L Blann, V Mohlabine, K le Roux, D Schnugh); (iii) J Thomas and G Ntshoe of the NICD for providing the monthly case numbers of laboratory-confirmed pertussis cases for SA; (iv) the clinical managers of Pelonomi, National District and Universitas hospitals for permission to collect the data; and (v) G Hussey for encouragement and advice with the manuscript.

1. Mulholland K. Measles and pertussis in developing countries with good vaccine coverage. Lancet 1995;345(8945):305-307. DOI:10.1016/S0140-6736 (95) 90282-1

2. Mooi FR, van der Maas NAT, de Melker HE. Pertussis resurgence: Waning immunity and pathogen adaptation - two sides of the same coin. Epidemiol Infect 2014;142(4):685-694. DOI:10.1017/ adaptation - two

3. Strebel P, Hussey G, Metcalf C, Smith D, Hanslo D, Simpson J. An outbreak of whooping cough in Strebel P, Hussey G, Metcalf C, Smith D, Hanslo D, Simpson J. An outbreak of whooping cough in
a highly vaccinated urban community. J Trop Pediatr 1991;37(2):71-76. DOI:10.1093/tropej/37.2.71 a highly vaccinated urban community. J Trop Pediatr 1991;37(2):71-76. DOI:10.1093/tropej/37.2.71
Hallbauer UM, Goosen Y, Pieters M. An outbreak of pertussis in Bloemfontein, South Africa, 20084. Hallbauer UM, Goosen Y, Pieters M. An outbreak of pertussis in Bloemfontein, S
2009. S Afr Fam Pract 2011;53(5):495-500. DOI:10.1080/20786204.2011.10874140

5. Forsyth K, Plotkin S, Tan T, Wirsing von König C. Strategies to decrease pertussis transmission to infants. Pediatrics 2015;135(6):e1475-1482. DOI:10.1542/peds.2014-3925

6. Statistics South Africa. Census 2011 Statistical Release - P0301.4/Statistics South Africa. Pretoria: SSA 2012. http://www.statssa.gov.za/publications/P03014/P030142011.pdf (accessed 9 July 2015)

7. Cherry JD, Heininger U. Pertussis and other Bordetella infections. In: Feigin RD, Cherry JD, Demmler G, Kaplan SL, eds. Textbook of Pediatric Infectious Diseases. 5th ed. Philadelphia: Saunders, 2004:1588-1608. 8. Health Systems Trust. DTP3 coverage. http://indicators.hst.org.za/healthstats/297/data (accessed 16 July 2015).

9. Corrigall J, Coetzee D, Cameron N. Is the Western Cape at risk of an outbreak of preventable childhood diseases? Lessons from an evaluation of routine childhood immunisation coverage. S Afr Med J 2008;98(1):41-45.

10. Heininger U, Weibel D, Richard J-L. Prospective nationwide surveillance of hospitalizations due Heininger U, Weibel D, Richard J-L. Prospective nationwide surveillance of hospitalizations due
to pertussis in children, 2006-2010. Pediatr Infect Dis I 2014;33(2):147-151. DOI:10.1097/01. to pertussis in children,
inf.0000435503.44620.74

11. Cherry JD, Tan T, Wirsing von König C, et al. Clinical definition of pertussis: Summary of a Global Pertussis Initiative roundtable meeting, February 2011. Clin Infect Dis 2012;54(12):1756-1764. DOI: $10.1093 / \mathrm{cid} / \mathrm{cis} 302$

12. Shakib J, Wyman L, Gesteland PH, et al. Should the pertussis case definition for public health reporting be refined? J Public Health Manag Pract 2009;15(6):479-484. DOI:10.1097/PHH.0b013e3181af0ac3

13. National Institute for Communicable Diseases, Division of the National Health Laboratory Service. Pertussis cluster. Communicable Diseases Communiqué 2009;8(2):3-4. http://www.nicd.ac.za/assets/ files/NICDCommFeb09Vol08_02.pdf (accessed 22 September 2015)

14. National Institute for Communicable Diseases, Division of the National Health Laboratory Service. Pertussis. Communicable Diseases Communiqué 2010;9(8):4-5.

15. National Institute for Communicable Diseases, Division of the National Health Laboratory Service. Pertussis. Communicable Diseases Communiqué 2011;10(2):1-2 http://www.nicd.ac.za/assets/files/ NICD\%20Communique\%20February\%202011(1).pdf (accessed 22 September 2015).

16. National Institute for Communicable Diseases, Division of the National Health Laboratory Service. Pertussis Communicable Diseases Communiqué 2015;14(6):4-6 http://www.nicd.ac.za/assets/files/NICD-NHLS\%20 Communicable Diseases Communique 2015;14(6):4-6 http://www.nicd.ac.za/assets/files/NICD-NHIS
Communicable\%20Disease\%20Communiqu\%C3\%A9_June\%202015.pdf (accessed 22 September 2015).

17. Healy CM, Rench MA, Baker CJ. Importance of timing of maternal combined tetanus, diphtheria, Healy CM, Rench MA, Baker CJ. Importance of timing of maternal combined tetanus, diphtheria,
and acellular pertussis (Tdap) immunization and protection of young infants. Clin Infect Dis 2013;56(4):539-544. DOI:10.1093/cid/cis923

18. Lugnér AK, van der Maas N, van Boven M, Mooi FR, de Melker HE. Cost-effectiveness of targeted vaccination to protect new-borns against pertussis: Comparing neonatal, maternal, and cocooning vaccination strategies. Vaccine 2013;31(46):5392-5397. DOI:10.1016/j.vaccine.2013.09.028

19. Heininger $U$. Vaccination of health care workers against pertussis: Meeting the need for safety within hospitals. Vaccine 2014;32(38):4840-4843. DOI:10.1016/j.vaccine.2013.10.062

Accepted 18 April 2016. 